\title{
Point-of-care Tests in Pediatric Infectious Diseases Practice
}

\section{Çocuk Enfeksiyon Hastalıkları Pratiğinde Hasta Yanı Tanı Testleri}

\author{
Mustafa Hacımustafaoğlu' \\ ' Department of Pediatrics, Department of Pediatric Infectious Diseases, Uludag University School of Medicine, Bursa, Turkey
}

Berna Özcan, MD

Question : What are the bedside diagnostic tests (point-of-care tests) and what are the roles of them in pediatric practice?

Cite this article as: Hacımustafaoğlu M, Özcan B. Point-of-care tests in pediatric infectious diseases practice. J Pediatr Inf 2019;13(3):e137-e139.

\section{Answer (Mustafa Hacımustafaoğlu, MD)}

With no exact equivalence in the Turkish language, "point-of-care" tests can be referred to as bedside tests, bedside diagnostic tests and chairside tests. In my opinion, the term "bedside diagnostic tests" is the most suitable among all, and hence, the term "bedside diagnostic tests" will be used as "point-of-care tests" in this article.

Bedside diagnostic tests are the tests that ran by doctors or other healthcare personnel at the point where the patient is seen (e.g. outpatient clinic, emergency service, observation room, healthcare center, and etc.) and are completed in a relatively short time. Following patient history and physical examination, these tests are practically important in terms of clinical decision-making, treatment planning, and also they results rapidly and contribute to the prognosis of the patient.

Bedside diagnostic tests are used widely and particularly in pediatric infectious diseases practice.

The bedside diagnostic tests used in pediatric infectious diseases practice can be classified in two major groups (Table 1):
1. Non-spesific bedside diagnostic tests: These include host biomarkers CRP, procalcitonin and also hemogram/formula leukocytes, peripheral smear, standard urine analysis, stool smear and microscopy. Some authors state that chest radiography can be regarded in this group if available. These are not aimed at the agent, but are related to the severity of the disease caused by the agent in the host body and can be used nonspecifically in the discrimination of bacteria-viral infections and/or in estimating the severity of the present infection/inflammation in some cases and in deciding upon hospitalization or emergency observation.

2. Bedside diagnostic tests aimed at specific agent: These are agent-specific tests; such as antigen testing for group A beta-hemolytic Streptococcus in throat swab sample, respiratory syncytial virus and/or influenza virus antigen tests in nasal and throat secretions or swab samples, rotavirus and adenovirus antigen in stool samples, and detection of tubercle bacillus in mucus samples (Xpert test). In some cases, some PCR-based tests which gives rapid results in respiratory tract secretion or swab samples are promising for the future and can be classified in bedside diagnostic tests.

Correspondence Address / Yazışma Adresi

Mustafa Hacımustafaoğlu

Uludağ Üniversitesi Tıp Fakültesi,

Çocuk Sağlığı ve Hastalıkları Anabilim Dalı,

Çocuk Enfeksiyon Hastalıkları Bilim Dalı,

Bursa-Türkiye

E-mail:mkemal@uludag.edu.tr

Received: 24.05.2019

Accepted: 25.05.2019 
Table 1. Classification of the bedside diagnostic tests

\begin{tabular}{|l|l|}
\hline Non-specific (aimed at host response) & Specific (aimed at the agent) \\
\hline Hemogram/formula leukocyte/peripheral smear & GAS antigen test \\
C-reactive protein & RSV antigen test \\
Procalcitonin & Influenza antigen test \\
Standard urinalysis (swab test and microscopy) & Rotavirus antigen test \\
Stool smear and microscopy & Adenovirus antigen test \\
(chest radiography) & Others (rapid PCR, Xpert/RIF-TB, and etc.) \\
\hline GAS: Group A streptoccoccus, RSV: Respiratory syncytial virus. & \\
\hline
\end{tabular}

Ideal bedside diagnostic tests should be those that are performed quickly and easily without troubling the child and his/her family (child and family-friendly test), give fast results (generally $<15 \mathrm{~min}$ ), are cheap and cost effective, and reliable (with high sensitivity and specifity). These tests must contribute positively to the treatment and monitoring of the patient by providing insight for a rational treatment approach. Moreover, these tests provide additional information, particularly in the field of infectious diseases, in terms of antibiotic use and duration. They are of utmost importance in rational antibiotic use. Quick resolution of the patient's problem at the point of examination contributes to the more productive use of healthcare services due to its advantages such as not being transferred to other institutions for laboratory works and not engaging the laboratory and physician for laboratory results. Furthermore, these tests contribute to the rational use of antibiotics with a low cost in small hospitals and healthcare centers where particularly polyclinic services are being given without extensive laboratory facilities and increase the efficiency of healthcare services in these types of healthcare institutions. The pros of these tests include their sufficient and satisfying accuracy and reliability, cost-efficiency, the fact that they are effective for decision-making in patient treatment and follow-up, and that they are standard, easy, patient-friendly, ideally concluded in $<15$ mins, and do not demand a high-level of experience.

Practical areas of use of the bedside diagnostic tests in pediatric infectious diseases: Hemogram/formula leukocyte and peripheral smear, CRP, procalcitonin can be used to evaluate bacterial-viral separation and the possibility of serious bacterial infection in a patient presenting with fever. According to the DMSA renal cortical scintigraphy which is the gold standard in acute pyelonephritis; the cutoff values of CRP $>20 \mathrm{mg} / \mathrm{L}$ and procalciton in $>0.5 \mathrm{ng} / \mathrm{mL}$ showed $94 \%$ and $86 \%$ sensitivity and $39 \%$ and $74 \%$ specificity, respectively. Elevated CRP and procalcitonin levels can also be used in supporting the diagnosis of bacterial pneumonia. In fevers without localizing sign, leukocytosis $\left(>15.000 / \mathrm{mm}^{3}\right)$ and elevated immature neutrophils (bands) $\left(>10 \%\right.$ or $>1500 / \mathrm{mm}^{3}$ ) in hemogram, elevated CRP and procalcitonin may support the presence of a systemic bacterial infection. In addition, presence of toxic granulation and toxic vacuolisation is considered as supportive findings of severe bacterial infection. Standard urinalysis and stool smear and microscopy evaluation are performed according to standard assesments and are useful in rapid diagnosis.

Rapid antigen tests (such as GAS, respiratory syncytial virus, influenza) are tests with fast results (generally $<1 \mathrm{~h}$ ) that can guide physicians to treatment in children with upper respiratory tract infection (URTI) and acute pharyngitis/tonsillitis/tonsillopharyngitis. The sensitivity and specifity of GAS and RSV rapid antigen tests are sufficiently high. If GAS test is positive, then there is no need for a throat culture. However, if GAS test is negative and the physician still considers the possibility of GAS, then a throat culture may be necessary for a $5-10 \%$ culture positivity.

There are different types of influenza rapid antigen tests whose costs, working methods, result time, sensitivity, and specifity differ from one another. Generally, the results can be obtained within hours or even within $<20$ mins according to the test used and laboratory facilities. RT-PCR, which is one of the tests extensively used in diagnosis, can differentiate influenza $A$ and $B$ and subtypes of influenza $A$. Its sensitivity varies between $86-100 \%$. In tests used in the detection of the antigen with direct and indirect immunofluorescent method, the result can be obtained within 1-4 hours, influenza $A$ types can be determined and their sensitivity is $70-100 \%$ while specifity is higher. Sensitivity and specifity of PCR and immunofluorescent antigen detection tests are much higher than the below-mentioned antigen tests with normal speeds.

Usual antigen detection methods can typically give results in $<15$ mins in influenza, differentiate influenza $A$ and $B$, and are cheaper and more easily accessible. The sensitivity of these methods have been shown as $54 \%$ for influenza $A$ and $53 \%$ for influenza B, and specifity as $100 \%$ for both influenza types in a metaanalysis. It has been demonstrated that sensitivity in children has been higher ( $61 \%$ versus $43 \%$ for influenza $A$ and $33 \%$ versus $66 \%$ for influenza B) compared to adults. If the test is positive in seasons when influenza prevalence is 
Table 2. Bedside diagnostic tests that can be used in pediatric infectious diseases practice

\begin{tabular}{|c|c|c|}
\hline Clinical picture & \multicolumn{2}{|c|}{ Bedside diagnostic tests to be used* } \\
\hline Acute pharyngitis/tonsillitis/tonsillopharyngitis & - & GAS rapid antigen test \\
\hline URTI/LRTI/Acute bronchiolitis & - & RSV rapid antigen test \\
\hline Acute gastroenteritis & Stool smear and microscopy & Rotavirus, adenovirus rapid antigen test \\
\hline Pneumonia & Hemogram/formula leukocyte CRP, PCT & \\
\hline Fever without localized sign & Hemogram/formul leukocyte, peripheral smear, CRP, PCT & \\
\hline
\end{tabular}

low, false positivity should be considered. False positivity can be seen in individuals taking care of pigs and poultry. Negative result of usual and rapid antigen detection methods does not rule out influenza disease and if the disease is suspected, ensuring diagnosis with a molecular method with high sensitivity like RT-PCR would be appropriate.

Table 2 shows cases when bedside diagnostic tests are frequently used in children in pediatric infectious disease practice. However, it should be kept in mind that these tests are more valuable in patients with no prior treatment history and that the patient may have been affected by the treatment he/ she has received before.

\section{References}

1. Keitel K, Lacroix L, Gervaix A. Point-of-care testing in pediatric infectious diseases. Pediatr Infect Dis J 2018;37:108-10.

2. Shaikh N, Borrell JL, Evron J, Leeflang MMG, et al. Procalcitonin, C-reactive protein, and erythrocyte sedimentation rate for the diagnosis of acute pyelonephritis in children. Cochrane Database Syst Rev 2015;1:CD009185.
3. Alcoba G, Keitel K, Maspoli V, Lacroix L, Manzano S, Gehri M, et al. Three-step diagnosis of pediatric pneumonia at the emergency department using clinical predictors, C-reactive protein, or procalcitonin, and pneumococcal or viral PCR. Eur J Pediatr 2017;176:815-24.

4. Committee On Infectious Diseases. Recommendations for prevention and control of influenza in children, 2017-2018. Pediatrics 2017; 140:e20172550.

5. Munoz FM. Seasonal influenza in children: clinical features and diagnosis https://www.uptodate.com/contents/seasonal-influenza-in-children-clinical-features-and-diagnosis (Accessed on 4 July 2018).

6. Merckx J, Wali R, Schiller I, Caya C, Gore GC, Chartrand C, et al. Diagnostic accuracy of novel and traditional rapid tests for influenza infection compared with reverse transcriptase polymerase chain reaction: a systematic review and meta-analysis. Ann Intern Med 2017;167:394-409.

7. Hacımustafaoğlu M. Akut tonsillofarenjitte etyolojik tanıda akılcı laboratuvar. J Pediatr Inf 2018;12:124-5.

8. Hacımustafaoğlu M. Akut faz belirteci olarak prokalsitonin. J Pediatr Inf 2017;11:196-7.

9. Hacımustafaoğlu M. Akut faz reaktanları (eritrosit sedimentasyon hızı, CRP). J Pediatr Inf 2017;11:53-5. 